\title{
A self sufficient energy model for poultry farms in Bangladesh to reduce greenhouse gas emission and increase energy efficiency
}

\author{
Mohammad Shariful Islam ${ }^{1}$, Asif Islam², Enamul Basher ${ }^{1}$ \\ ${ }^{1}$ Electrical \& Electronic Engineering, Bangladesh University of Engineering \& Technology (BUET), Dhaka, Bangladesh \\ ${ }^{2}$ Planning \& Development Division, Power Grid Company of Bangladesh (PGCB) Ltd., Dhaka, Bangladesh
}

\section{Email address:}

Sabuz03@gmail.com (M. S. Islam), asif038@gmail.com (A. Islam), enamul_basher@eee.buet.ac.bd (E. Basher)

\section{To cite this article:}

Mohammad Shariful Islam, Asif Islam, Enamul Basher. A Self Sufficient Energy Model for Poultry Farms in Bangladesh to Reduce Greenhouse Gas Emission and Increase Energy Efficiency. International Journal of Renewable and Sustainable Energy.

Vol. 2, No. 4, 2013, pp. 153-162. doi: 10.11648/j.jirse.20130204.14

\begin{abstract}
There are over two hundred thousand of poultry farms in Bangladesh. With the annual growth rate of twenty five percent, the number is increasing rapidly. Most of these poultry farms draw their required electricity from the national grid; few of them use natural gas or diesel generators as the sources of energy. Very small numbers of them use poultry droppings for producing biogas to generate electricity and for cooking. But these biogas plants barely run at the peak of their capacity. The over reliance on national grid and fossil fuels aids to the emission of greenhouse gases and it is going to spiral up every year. But the poultry farms can produce their own energy from the poultry droppings which will reduce annual costs, greenhouse gas emission and they can even produce fertilizer from the biogas plant which will add to the generated revenue. The aim of this study is to divulge the possibility of self sufficient poultry farms using their poultry droppings only. A comparison is made among the annual costs, energy efficiency and greenhouse gases emissions from different sources of energy or different mix of them. It has been found that co-production of electricity and fertilizer optimizes the mentioned constraints.
\end{abstract}

Keywords: Greenhouse Gas, Bio-Energy, Poultry Dropping, Natural Gas, Energy Efficiency

\section{Introduction}

Bangladesh has over two hundred thousand of poultry farms. Most of the farms are using grid power. Only few of them produce their own power using natural gas. But as natural gas is not available in Bangladesh in abundance hence it is not the best of the solutions. Few of them are producing a portion of electricity from the daily poultry waste [1]. They use only a portion of daily poultry waste and remainder portion is lost. But all these poultry farms can become self sufficient in terms of energy using all daily wastes and with proper planning [2]. Even they can sell energy to the adjacent area. Proper planning refers to the smart use of resources to make the maximum out of limited resources [3]. There are different sources of energy for supplying these poultry farms e.g.-national grid, wind, solar, natural gas, biogas without fertilizer production, biogas with fertilizer production etc. All these sources have different pros and cons. Energy from these sources produce at different prices. Besides they have different energy efficiency and emits different amount of greenhouse of gases [4-7]. In this study an attempt will be made to select the right mix of energy for poultry farms from conventional and renewable energy sources so that costs and greenhouse gases emission are reduced, and plant efficiency and utilization are increased.

\section{Modeling a Self Sufficient Poultry Farm}

The main constraints of power generation are to reduce costs, increase the efficiency, reduce greenhouse gases and increase the plant utilization. Generation planning for a poultry farm can be divided into following steps [8-11].

- Capacity planning in the perspective of cost, energy consumption (efficiency) and greenhouse gas reduction. The purpose of this is to find the right mix of energy from conventional and renewable 
sources. As the renewable sources reduce the greenhouse gases [12], the primary aim would be to use as much renewable energy as possible.

- Optimal unit sizing for power system [13-16] with biogas plant only; as the biogas is the only renewable energy source considered for this study the aim of this part is to select the optimum size and number of biogas generator so that it will satisfy biggest portion of energy demand at lowest cost.

\subsection{Optimum Generation Mix in the Perspective of Cost, Energy Consumption and Greenhouse Gas Reduction}

In Bangladesh the different mix of grid energy, natural gas energy, diesel energy and biogas energy are used at different poultry farms. These energies come at different costs. But grid energy is not sufficient to satisfy the demand, natural gas is scarce, diesel is costly. Besides, all the conventional sources produce huge amount of green house gases. Hence the purpose of the capacity plan is to select the right mix of this energy sources to reduce costs, energy consumptions and greenhouse gases. There are different attempts made to find the right mix of energy from different sources by different persons for the national grid. Fuzhan Nasiri and G.H. Huang made one such attempt [17] in their work "Capacity Planning for Electricity Generation with Energy-Environmental Targets" for the national grid of Canada. That work was for grid connected power sources. The aim of this work is to make the poultry farms self sufficient so that no power has to be taken from the national grid. Any short fall will be addressed by the existing power sources e.g.- natural gas, diesel etc [1-2]. For this autonomous operation right modifications are made for the processes described by Fuzhan Nasiri and G.H. Huang [17].

Suppose there is n number of generators in a system then goal of the planning is to minimize the total cost of generation (TCG), emission of greenhouse gases (EGHG) and total internal energy consumption (TIEC). For optimization of the capacity there are multi objective functions subject to some constraints [18-21].

Suppose there is $n$ number of generators in the system and every generator produces $m$ unit of electricity. Then the equation of total costs of generation (TCG) is given by the equation 1 [2].

$$
\mathrm{TCG}=\sum_{\mathrm{i}=1}^{\mathrm{n}} \mathrm{C}_{\mathrm{i}}+\sum_{\mathrm{i}=1}^{\mathrm{n}} \mathrm{OM}_{\mathrm{i}}+\sum_{\mathrm{i}=1}^{\mathrm{n}} \sum_{\mathrm{j}=1}^{\mathrm{m}} \mathrm{G}_{\mathrm{ij}} \mathrm{T}_{\mathrm{ij}}+\Delta \mathrm{C}
$$

Here,

TCG $=$ Total cost of generation

$\mathrm{C}_{\mathrm{i}}=$ Capital cost of $\mathrm{i}$-th generator per year.

$\mathrm{OM}_{\mathrm{i}}=$ Operation and maintenance cost of $\mathrm{i}$-th generator per year.

$\mathrm{G}_{\mathrm{ij}}=$ Unit of electricity generated by $\mathrm{i}$-th generator per year.

$\mathrm{T}_{\mathrm{ij}}=$ Fuel cost of per unit electricity generation from i-th generator

$\Delta \mathrm{C}=$ Additional cost for additional capacity requirement

The emission of greenhouse gases (EGHG) is given by the equation 2 below [3],

$$
E G H G=\sum_{i=1}^{n} \sum_{j=1}^{m} G_{i j} E_{i j}
$$

Here,

$\mathrm{EGHG}=$ Emission of greenhouse gases

$\mathrm{EM}_{\mathrm{ij}}=$ Emission of greenhouse gases per unit electricity generation from $i$-th generator

Total internal energy consumption (TIEC) is given by the equation 3 below [3],

$$
\text { TIEC }=\sum_{\mathrm{i}=1}^{\mathrm{n}} \sum_{\mathrm{j}=1}^{\mathrm{m}} \mathrm{G}_{\mathrm{ij}} \mathrm{EC}_{\mathrm{ij}}
$$

Here,

$\mathrm{EC}_{\mathrm{ij}}=$ Internal energy consumption per unit electricity generation from $i$-th generator

The objective of the study is to minimize TCG, EGHG and TIEC subject to the following constrains. The constraints are,

$$
\begin{gathered}
\sum_{\mathrm{i}=1}^{\mathrm{n}}\left(\mathrm{S}_{\mathrm{i}}\right)+\Delta \mathrm{S} \geq \mathrm{L}_{\mathrm{p}}(1+\mathrm{r}) \\
\mathrm{G}_{\mathrm{i}} \leq\left(\mathrm{S}_{\mathrm{i}}+\Delta \mathrm{S}\right) \mathrm{R}_{\mathrm{i}} \\
\mathrm{G}_{\mathrm{i}} \geq \mathrm{L}_{\mathrm{fi}}\left(\mathrm{S}_{\mathrm{i}}+\Delta \mathrm{S}\right) \mathrm{RP}_{\mathrm{i}} \\
\mathrm{S}_{\mathrm{i}} \geq 0 \\
\mathrm{G}_{\mathrm{i}} \geq 0
\end{gathered}
$$

Here,

$\mathrm{S}_{\mathrm{i}}=$ Current generation capacity of $\mathrm{i}$-th generator

$\Delta \mathrm{S}=$ Additional generation capacity required

$\mathrm{L}_{\mathrm{p}}=$ Peak load

$\mathrm{r}=$ Reserve capacity $(\%)$

$\mathrm{L}_{\mathrm{fi}}=$ Loading factor of $\mathrm{i}$-th generator

$\mathrm{R}_{\mathrm{i}}=$ Running time of $\mathrm{i}$-th generator $=365 * 24 * \mathrm{~L}_{\mathrm{fi}}=8760 \mathrm{~L}_{\mathrm{fi}}$

$\mathrm{RP}_{\mathrm{i}}=$ Peak load time of $\mathrm{i}$-th generator

The objective functions described in equation 1,2 and 3 are optimized by the constraints described in equation 4 to 8. From optimized values the optimality of different cases is calculated and they are ranked as per optimality. The different values of TCG, EGHG and TIEC constitute three different sets denoted by TCG(c), EGHG(c) and TIEC(c) respectively. Here, $\mathrm{c}$ is the element of set of all cases. The $\mathrm{k}$-th value of all these sets is denoted by TCG $(\mathrm{k})$, EGHG (k) and TIE (k). The optimality of TCG, EGHG and TIE is given by,

$$
\begin{aligned}
\Psi_{\mathrm{TCG}}(\mathrm{k}) & =\frac{\operatorname{Max}(\mathrm{TCG}(\mathrm{c}))-\mathrm{TCG}(\mathrm{k})}{\operatorname{Max}(\mathrm{TCG}(\mathrm{c}))-\operatorname{Min}(\mathrm{TCG}(\mathrm{c}))} \\
\Psi_{\mathrm{EGHG}}(\mathrm{k}) & =\frac{\operatorname{Max}(\mathrm{EGHG}(\mathrm{c}))-\mathrm{EGHG}(\mathrm{k})}{\operatorname{Max}(\mathrm{EGHG}(\mathrm{c}))-\operatorname{Min}(\mathrm{EGHG}(\mathrm{c}))} \\
\Psi_{\mathrm{TIEC}}(\mathrm{k}) & =\frac{\operatorname{Max}(\operatorname{TIEC}(\mathrm{c}))-\operatorname{TIEC}(\mathrm{k})}{\operatorname{Max}(\operatorname{TIEC}(\mathrm{c}))-\operatorname{Min}(\operatorname{TIEC}(\mathrm{c}))}
\end{aligned}
$$

Here,

$\Psi_{\mathrm{TCG}}(\mathrm{k})=$ Optimality of total generation cost (TCG) of $\mathrm{k}$-th case

$\psi_{\mathrm{EGHG}}(\mathrm{k})=$ Optimality of emission of greenhouse gases 
(EGHG) of k-th case

$\psi_{\text {TIEC }}(\mathrm{k})=$ Opimality of total internal energy consumption (TIEC) of $\mathrm{k}$-th case

$\mathrm{c}=$ element of set of all cases

$\mathrm{k}=\mathrm{k}$-th element of the set

As the main purpose of the study to reduce the costs as well as the greenhouse gas emission hence $\psi_{\mathrm{TCG}}(\mathrm{k})$ will have the highest weights for calculating the overall optimality. $\psi_{\mathrm{EGHG}}(\mathrm{k})$ would secure half of weight of $\psi_{\text {TCG }}(\mathrm{k})$ and $\psi_{\text {TIEC }}(\mathrm{k})$ will get half of weight of $\psi_{\mathrm{EGHG}}(\mathrm{k})$. If the weight of $\psi_{\mathrm{TCG}}(\mathrm{k}), \psi_{\mathrm{EGHG}}(\mathrm{k})$ and $\psi_{\mathrm{TIEC}}(\mathrm{k})$ is $\mathrm{m}_{\mathrm{TCH}}$, $m_{E G H G}, m_{\text {TIEC }}$ respectively then the weight of the overall optimality can be calculated as follows,

$$
\begin{gathered}
\psi(\mathrm{k})=\underset{\mathrm{TCH}_{\mathrm{TIEC}}(\mathrm{k})}{\mathrm{m}_{\mathrm{TCH}} * \psi_{\mathrm{TCG}}(\mathrm{k})+\mathrm{m}_{\mathrm{EGHG}} * \psi_{\mathrm{EGHG}}(\mathrm{k})+\mathrm{m}_{\mathrm{TIEC}} *} \\
\psi(\mathrm{k})=\left[\begin{array}{lll}
\mathrm{m}_{\mathrm{TCG}} & \mathrm{m}_{\mathrm{EGHG}} & \mathrm{m}_{\mathrm{TIEC}}
\end{array}\right]\left[\begin{array}{c}
\psi_{\mathrm{TCG}}(\mathrm{k}) \\
\psi_{\mathrm{EGHG}}(\mathrm{k}) \\
\psi_{\mathrm{TIEC}}(\mathrm{k})
\end{array}\right]
\end{gathered}
$$

The values of weights can be calculated as,

$$
\mathrm{m}_{\mathrm{TCG}}+\mathrm{m}_{\mathrm{EGHG}}+\mathrm{m}_{\mathrm{TIEC}}=1
$$

But,

$$
\begin{gathered}
\mathrm{m}_{\mathrm{EGHG}}=\frac{\mathrm{m}_{\mathrm{TCG}}}{2} \\
\mathrm{~m}_{\mathrm{TIEC}}=\frac{\mathrm{m}_{\mathrm{EGHG}}}{2}=\frac{\mathrm{m}_{\mathrm{TCG}}}{4}
\end{gathered}
$$

Using equation 14, 15 and 16,

$$
\mathrm{m}_{\mathrm{TCG}}+\frac{\mathrm{m}_{\mathrm{TCG}}}{2}+\frac{\mathrm{m}_{\mathrm{TCG}}}{4}=1
$$

Solving equation 15,16 and 17 ,

$$
\left[\begin{array}{lll}
\mathrm{m}_{\mathrm{TCG}} & \mathrm{m}_{\mathrm{EGHG}} & \mathrm{m}_{\mathrm{TIEC}}
\end{array}\right]=\left[\begin{array}{lll}
0.571 & 0.285 & 0.142
\end{array}\right]
$$

\subsection{Optimal Unit Sizing for Power System with Biogas Plant Only}

It is very important to have optimum unit size and capacity reserve for a standalone power system for reliable operation. Without substantial capacity reserve any special requirement could not be addressed and it could lead to complete failure of the power system [22-25]. Besides, over dimensioning could lead to the hiking of cost. The objective of this part is to determine optimum unit sizing to reduce cost, reliable operation and substantial capacity reserve. There are different objective functions which are subject to optimization by some constraints,

Total costs per year must be minimized. The costs includes capital costs, and operation and maintenance costs Hence shall calculate the cost of generating electricity with $1,2,3,4,5 \ldots$ number of generators.

$$
\text { Minimize TCG }=\sum_{\mathrm{i}=1}^{\mathrm{n}} \mathrm{C}_{\mathrm{i}}+\sum_{\mathrm{i}=1}^{\mathrm{n}} \mathrm{OM}_{\mathrm{i}}+\Delta \mathrm{C}
$$

Here,

$\mathrm{TCG}=$ Total cost of generation
$\mathrm{C}_{\mathrm{i}}=$ Capital cost of $\mathrm{i}$-th generator per year.

$\mathrm{OM}_{\mathrm{i}}=$ Operation and maintenance cost of $\mathrm{i}$-th generator per year.

$\Delta \mathrm{C}=$ Additional cost for additional capacity requirement from other sources

Unused biogas can be used for other purposes e.g.cooking, water heating [26]. This unused biogas could even be sold as LPG. So, substantial revenue could be generated from this unused gas. The other objective of optimum unit sizing is to maximize this unused biogas,

$$
\mathrm{B}_{\mathrm{U}}=\mathrm{B}_{\mathrm{T}}-\mathrm{B}_{\mathrm{C}}
$$

Here,

$\mathrm{B}_{\mathrm{U}}=$ Unused Biogas per Year $\left(\mathrm{m}^{3}\right)$

$\mathrm{B}_{\mathrm{T}}=$ Total Biogas Produced per Year $\left(\mathrm{m}^{3}\right)$

$\mathrm{B}_{\mathrm{C}}=$ Total Biogas Consumed per Year $\left(\mathrm{m}^{3}\right)$

Per unit generation cost depends on the plant capacity factor. Greater the plant capacity factor (PCF) less the per unit generation cost. The aim of optimal unit sizing is to maximize the plant capacity factor,

$$
\mathrm{f}_{\mathrm{c}}=\frac{\mathrm{G}_{\mathrm{A}}}{8760 \mathrm{C}_{\mathrm{P}}}
$$

Here,

$\mathrm{f}_{\mathrm{c}}=$ Annual plant capacity factor

$\mathrm{G}_{\mathrm{A}}=$ Annual output $(\mathrm{kWh})$

$\mathrm{C}_{\mathrm{P}}=$ Plant Capacity $(\mathrm{kw})$

It has to maximize the ratio of hours full load operation to total operation (Plant Utilization Factor). It is the ratio of $\mathrm{kWh}$ generated to the product of plant capacity and the number of hours for which the plant was in operation.

$$
\mathrm{f}_{\mathrm{U}}=\frac{\mathrm{s}_{\mathrm{A}}}{\mathrm{C}_{\mathrm{P}} \mathrm{t}}
$$

Here,

$\mathrm{f}_{\mathrm{U}}=$ Plant Utilization factor

$\mathrm{S}_{\mathrm{A}}=$ Station output in $\mathrm{kWh}$

$\mathrm{C}_{\mathrm{P}}=$ Plant Capacity (kw)

$\mathrm{t}=$ hours of operation

Equations 19 to 22 are to be optimized under few constraints. The constraints are.

LOLP $=1$ day/year

$\mathrm{H}_{\mathrm{OO}}=16$ hours/day/generator

$\mathrm{T}_{\text {HOOY }}=(365-$ LOLP $) * 16=5824$

$\mathrm{E}_{\mathrm{i}}=10.5 \mathrm{Tj} / \mathrm{GWh}$

Here,

LOLP $=$ Loss of Load Probability (LOLP)

$\mathrm{H}_{\mathrm{OO}}=$ Hours of operation per day per generator

$\mathrm{T}_{\text {HOOY }}=$ Total hours of operation per year

$\mathrm{E}_{\mathrm{i}}=$ Energy intensity

From equation 19, 20, 21 and 22 sets of values of TCG, $B_{U}, T_{C}$ and $T_{U}$ are found for different combinations of generators units. These sets are denoted as TCG (c), $B_{U}(c)$, $T_{C}(c)$ and $T_{U}(\mathrm{c})$. Where, $\mathrm{c}$ is the element of set of all cases. The k-th value of all these sets are denoted by TCG $(\mathrm{k})$, $B_{U}(k), T_{C}(k)$ and $T_{U}(\mathrm{k})$. The optimality of TCG, $B_{U}, T_{C}$ and $T_{U}$ are given by, 


$$
\begin{gathered}
\mu_{\mathrm{TCG}}(\mathrm{k})=\frac{\operatorname{Max}(\mathrm{TCG}(\mathrm{c}))-\mathrm{TCG}(\mathrm{k})}{\operatorname{Max}(\mathrm{TCG}(\mathrm{c}))-\operatorname{Min}(\mathrm{TCG}(\mathrm{c}))} \\
\mu_{\mathrm{B}_{\mathrm{U}}}(\mathrm{k})=1-\frac{\operatorname{Max}\left(\mathrm{B}_{\mathrm{U}}(\mathrm{c})\right)-\mathrm{B}_{\mathrm{U}}(\mathrm{k})}{\operatorname{Max}\left(\mathrm{B}_{\mathrm{U}}(\mathrm{c})\right)-\operatorname{Min}\left(\mathrm{B}_{\mathrm{U}}(\mathrm{c})\right)} \\
\mu_{\mathrm{T}_{\mathrm{C}}}(\mathrm{k})=1-\frac{\operatorname{Max}\left(\mathrm{T}_{\mathrm{C}}(\mathrm{c})\right)-\mathrm{T}_{\mathrm{C}}(\mathrm{k})}{\operatorname{Max}\left(\mathrm{T}_{\mathrm{C}}(\mathrm{c})\right)-\operatorname{Min}\left(\mathrm{T}_{\mathrm{C}}(\mathrm{c})\right)} \\
\mu_{\mathrm{T}_{\mathrm{U}}}(\mathrm{k})=1-\frac{\operatorname{Max}\left(\mathrm{T}_{\mathrm{U}}(\mathrm{c})\right)-\mathrm{T}_{\mathrm{U}}(\mathrm{k})}{\operatorname{Max}\left(\mathrm{T}_{\mathrm{U}}(\mathrm{c})\right)-\operatorname{Min}\left(\mathrm{T}_{\mathrm{U}}(\mathrm{c})\right)}
\end{gathered}
$$

Here,

$\mu_{\mathrm{TCG}}(\mathrm{k})=$ Optimality of total generation cost (TCG) of kth case

$\mu_{\mathrm{B}_{\mathrm{U}}}(\mathrm{k})=$ Optimality of biogas usage of $\mathrm{k}$-th case

$\mu_{\mathrm{T}_{\mathrm{C}}}(\mathrm{k})=$ Opimality of plant capacity factor of $\mathrm{k}$-th case

$\mu_{\mathrm{T}_{\mathrm{U}}}(\mathrm{k})=$ Opimality of plant utilization factor of $\mathrm{k}$-th case

The optimality of biogas usage is found by taking the average of optimality of additional biogas equivalent energy requirement and unused biogas. The optimality of plant utilization $\left(\mu_{U}\right)$ is found by taking the average of $\mu_{\mathrm{T}_{\mathrm{C}}}(\mathrm{k})$ and $\mu_{\mathrm{T}_{\mathrm{U}}}(\mathrm{k})$.

$$
\mu_{U}(k)=\frac{\mu_{\mathrm{T}_{\mathrm{C}}}(\mathrm{k})}{\mu_{\mathrm{T}_{\mathrm{U}}}(\mathrm{k})}
$$

Final optimality $(\mu(\mathrm{k}))$ is found by taking the average of $\mu_{\mathrm{TCG}}(\mathrm{k}), \mu_{\mathrm{B}_{\mathrm{U}}}(\mathrm{k})$, and $\mu_{\mathrm{U}}(\mathrm{k})$.

$$
\mu(\mathrm{k})=\frac{\mu_{\mathrm{TCG}}(\mathrm{k})+\mu_{\mathrm{B}_{\mathrm{U}}}(\mathrm{k})+\mu_{\mathrm{U}}(\mathrm{k})}{3}
$$

\section{Results and Analysis}

\subsection{Study Area}

For case study Paragon Poultry Limited (PPL) was surveyed for real time information on present. The location of PPL is $50 \mathrm{~km}$ from the centre (Gulistan) of Dhaka. It is in Gazipur Sadar Upazila under Gazipur District in Dhaka division. The electricity is distributed by Rural Electrification Board (REB) in that area. Paragon Poultry Limited (PPL) produces its own electricity. So they don't need to buy electricity from REB. Table 1 shows the details of the location for case study [3].

Table 1. Detail of Paragon Poultry Limited (PPL)

\begin{tabular}{ll}
\hline Case Study Location Details & \\
\hline Site Name & Paragon Poultry Limited (PPL) \\
GPS & $90^{\circ} 25^{\prime} 22.1^{\prime \prime} / 24^{\circ} 9^{\prime} 7.9^{\prime \prime}$ \\
Distance from Dhaka & $50 \mathrm{~km}$ \\
Approximate Area & $0.5 \mathrm{sqr}$ km \\
Power Distributed in the Area By & Rural Electrification Board (REB) \\
Power Sources & Own Source (Natural \& Biogas) \\
Number of Sheds & 24 \\
Number of Birds & 264000 \\
Birds Type & Breeder \\
Terrain Type & Rural \\
\hline
\end{tabular}

\subsection{Present Scenario of Power Consumption by PPL}

PPL have three $500 \mathrm{kw}$ natural gas generators, one $260 \mathrm{kw}$ biogas generator and one $200 \mathrm{kw}$ diesel generator. Biogas generator is used as base power generator and runs for almost 24 hours. Natural gas generators supply the peak power and diesel generator is kept as standby for emergency usage. Figure 1 below shows the monthly power consumption by PPL.

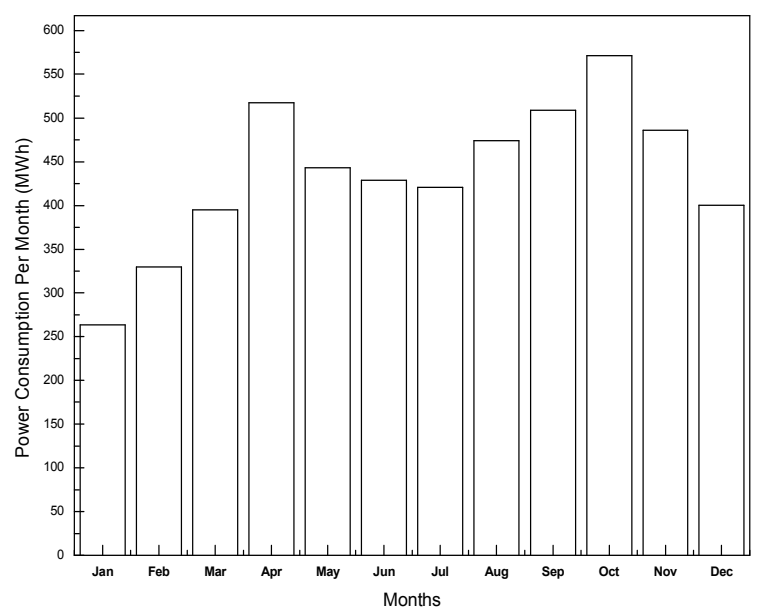

Fig 1. Monthly Power Consumptions (MWh) in 2012 (Source: PPL)

Figure 1 shows that October has the highest energy consumption followed by April and September. From May to August the energy consumption remains contestant. January sees the lowest energy consumption followed by February. A load curve is a chart showing the amount of electrical energy customer's use over the course of time. Power producers' use this information to plan how much electricity they will need to make available at any given time. Daily load curve shows the hourly power consumption for 24 hours of the day. Figure 2 shows the month wise daily load curve of PPL.

During 0 to 6 hours the energy consumption remains the lowest. This is the base load of PPL, which varies over the year as well as over the months and days. During the 6 hours to 10 hours and 22 hours to 24 hours the energy consumption increases. Energy consumption is the highest at the evening till 22 hours. This is the peak load of PPL, which varies over the year as well as over the months and days. During the day time the energy consumption remains high but not as high as the evening (Figure 2). The overall load factor of PPL calculated from the load curve is about $55 \%$. From above curves it is clear that there are five distinct ranges of energy consumptions. For cost optimization purpose we need to supply power with different unit size during that time. 

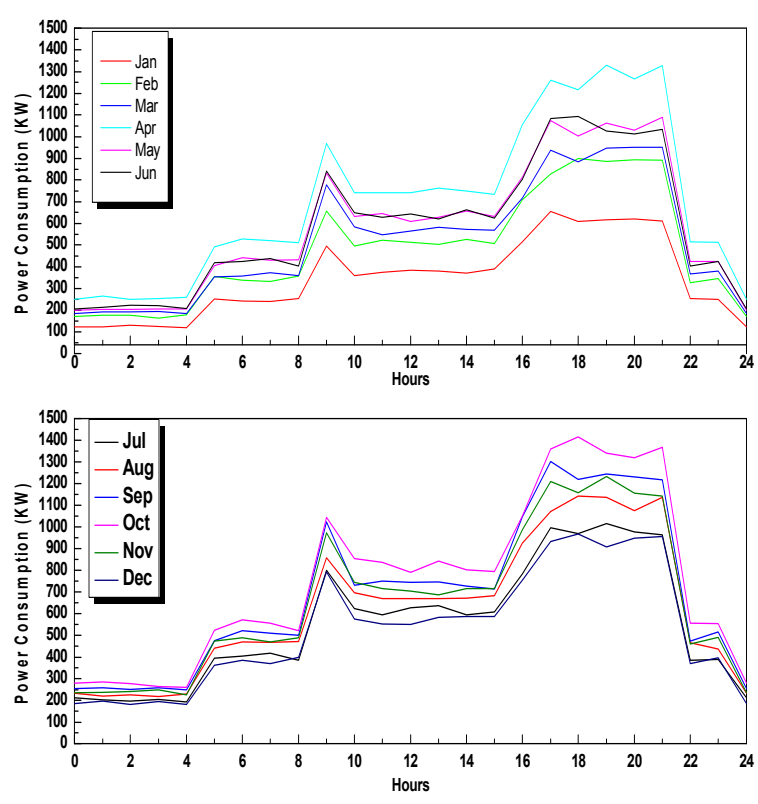

Fig 2. Month wise daily load curve for PPL (Source: PPL)

A load duration curve illustrates the variation of a certain load in a downward form such that the greatest load is plotted in the left and the smallest one in the right. On the time axis, the time duration for which each certain load continues during the day is given. There are some facts about the LDC and can be summarized as,

- The LDC is an arrangement of all load levels in a descending order of magnitude.

- The area under the LDC represents the energy demanded by the system (consumed).

- Can be used in economic dispatching, system planning and reliability evaluation.

- It is more convenient to deal with it than the load curve.

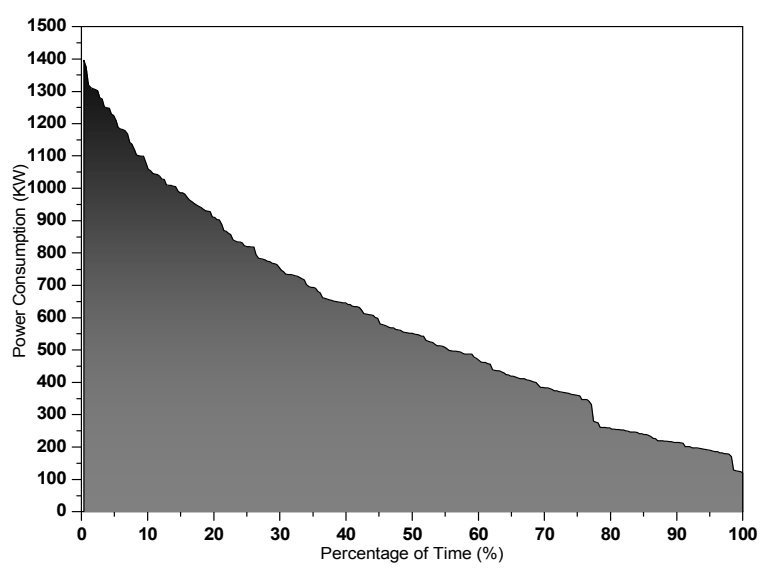

Fig 3. Load Duration Curve in 2012 (Source: PPL)

A LDC is similar to a load curve but the demand data is ordered in descending order of magnitude, rather than chronologically. The LDC curve shows the capacity utilization requirements for each increment of load. The height of each slice is a measure of capacity, and the width of each slice is a measure of the utilization rate or capacity factor. The product of the two is a measure of electrical energy (e.g. kilowatt-hours) (Figure 3).

The base load is about $160 \mathrm{KW}$. So PPL must have a minimum generation of $160 \mathrm{KW}$ for 24 hours a day for all 365 days of the year.

\subsection{Optimum Generation Mix in the Perspective of Cost, Energy Consumption and Greenhouse Gas Reduction}

There could be different sources of power in the perspective of Bangladesh e.g.-National grid, natural gas, diesel, solar, wind power, biogas without fertilizer production and biogas with fertilizer production. The sources of energy could be any mix of above mentioned sources. Presently PPL uses natural gas for supplying power to their site. They don't have connection from nation grid. The below table 2 summarizes the present scenario.

Table 2. Present Cost of Fuel for per kwh Electricity Generation from Natural Gas (BDT/kwh) (Source: PPL)

\begin{tabular}{cccc}
\hline Months & $\begin{array}{c}\text { Natural Gas } \\
\text { Consumption per } \\
\text { month (cu m) }\end{array}$ & $\begin{array}{c}\text { Total Power } \\
\text { Production } \\
\text { from Natural } \\
\text { Gas per } \\
\text { Month (kwh) }\end{array}$ & $\begin{array}{c}\text { Cost for } \\
\text { Natural Gas } \\
\text { per Month } \\
\text { (USD) }\end{array}$ \\
\hline Jan & 63,965 & 263,285 & 3,146 \\
Feb & 79,978 & 329,188 & 3,933 \\
Mar & 94,642 & 389,550 & 4,654 \\
Apr & 122,246 & 503,155 & 6,012 \\
May & 103,401 & 425,588 & 5,085 \\
Jun & 98,770 & 406,528 & 4,857 \\
Jul & 95,752 & 394,107 & 4,709 \\
Aug & 104,814 & 431,405 & 5,154 \\
Sep & 107,380 & 441,966 & 5,281 \\
Oct & 117,459 & 483,451 & 5,776 \\
Nov & 88,742 & 365,245 & 4,364 \\
Dec & 56,180 & 231,230 & 2,763 \\
Total & $1,133,329$ & $4,664,698$ & 55,733 \\
\hline
\end{tabular}

Power from all mentioned sources comes at different costs. The capital costs are different, fuel costs are different and the operation and maintenance costs are different. The below table 3 summarizes different costs incurred by different sources of power. The cost of per MWh electricity generation is calculated at Sandwip in Bangladesh is about 103USD. But as the area at which PPL is situated has half the wind power density (WPD) of Sandwip hence it can be safely presumed that the costs will be doubled. For the case of biogas with fertilizer additional revenue is generated selling fertilizer. The grid power is supplied at a rate of 76.5 UDS per MWh. The cost of solar remains high and subject to availability of sunshine. The biogas generation plant can be implemented by local equipments or imported equipments. A mixture of local and imported equipments is assumed to be implemented. The costs for biogas plants are supplied by the PPL themselves. The costs mentioned here 
are to sum of capital and O\&M costs.

Table 3. Cost and Revenue of Electricity Generation

\begin{tabular}{ccc}
\hline Power Sources & $\begin{array}{c}\text { Total Costs for } \\
\text { electricity } \\
\text { Generation } \\
\text { (USD/MWh) }\end{array}$ & $\begin{array}{c}\text { Revenue } \\
\text { Generation } \\
\text { (USD/MWh) }\end{array}$ \\
\hline National grid & 76.5 & 0.0 \\
Natural Gas & 39.6 & 0.0 \\
Diesel & 194.1 & 0.0 \\
Solar & 1070.0 & 0.0 \\
Wind power & 206.0 & 0.0 \\
Biogas & 62.8 & 0.0 \\
Biogas with Fertilizer & 238.7 & 339.3 \\
\hline
\end{tabular}

Power from national grid, natural gas, diesel, solar, wind power and biogas without fertilizer production incur annual costs for capital, fuels and O\&M. But biogas with fertilizer production generates revenue which suppresses the costs incurs by the capital, fuel costs and O\&M costs. Hydropower, nuclear power and coal power are not taken into consideration as they are either not feasible or not available for micro scale usage. The poultry farms can choose any sources of energy or different fractions of them. For reducing the costs different fractions of energy from different sources are marked as different number of cases. Costs of all these cases are calculated using table 3. There are 126 different cases are marked for study for choosing the right mix of energy. The different cases are given by the figure 4 below,

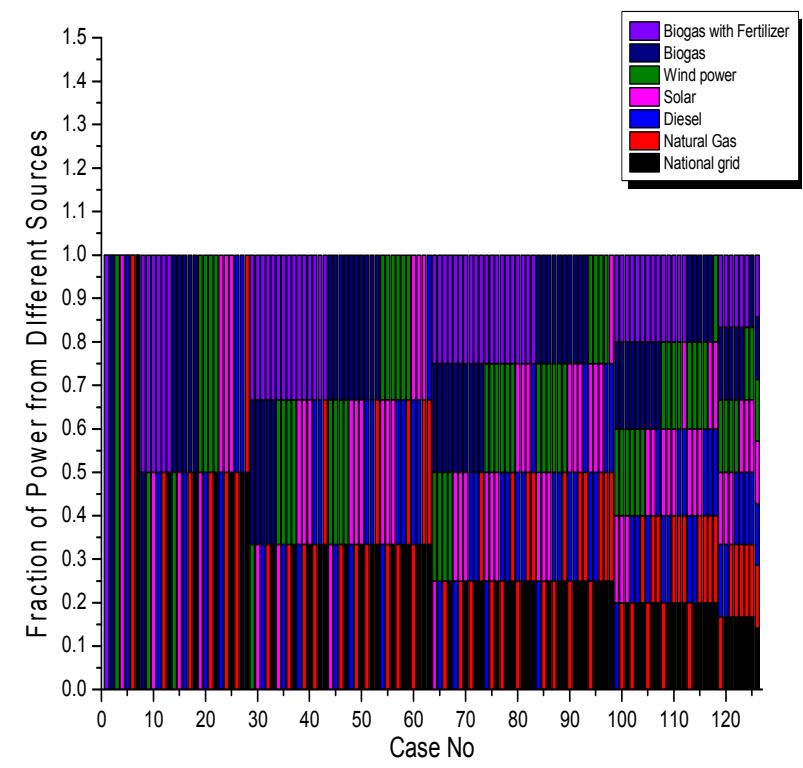

Fig 4. Different cases based on the fraction of different energy sources

For the loads mentioned in the figure 1, 2 and 3 total annual costs, annual revenue and annual net costs are calculated using table 3 . The figure 5 shows the annual costs, revenues and net costs.

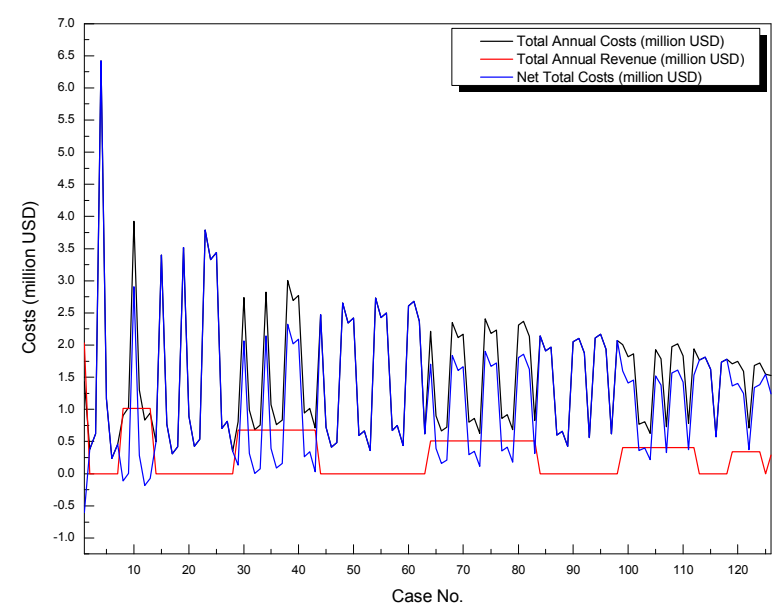

Fig 5. Different cases based on the fraction of different energy sources

The figure 5 shows that annual costs vary with variations of fractions from different sources. Biogas with fertilizer production generates revenues hence generation mix of $100 \%$ biogas with fertilizer production has a negative net costs which means it is economically profitable. There are few other cases where $50 \%$ fraction of biogas with fertilizer and natural gas or grid power is used are economically profitable. The optimality of all these cases is calculated using equation 9. The optimality of all these cases are shown by the figure 6 below,

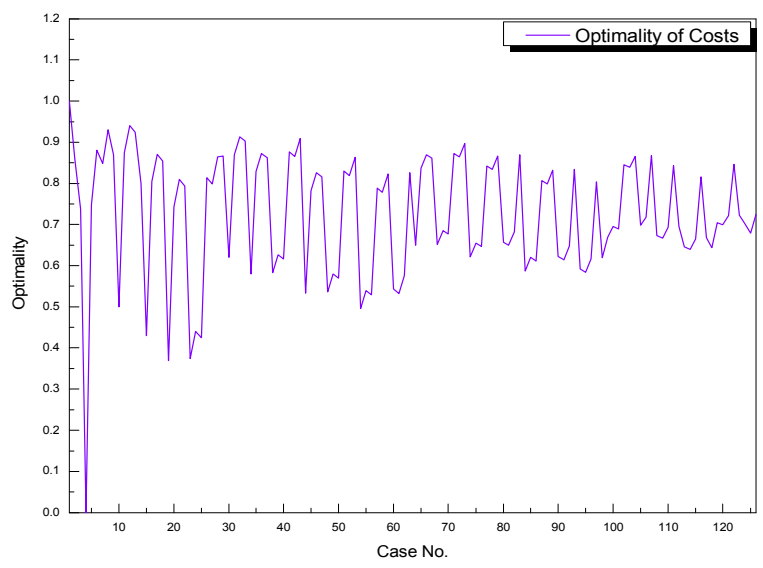

Fig 6. Optimality of costs of different cases based on the energy mix mentioned in figure 4.

Figure 6 show that case 1 which is $100 \%$ biogas with fertilizer production has the highest optimality of 1 . There are other cases where optimality is over 0.9 . The optimality of cost is not sufficient condition for selecting the right mix of generation. It also needs to reduce the total internal energy consumption (TIEC) and emission of greenhouse gases (EGHG). Below table 4 shows the TIEC and EGHG for all seven energy sources mentioned earlier. In Bangladesh $67.38 \%$ power comes from natural gas, 27.37 from diesel, $2.75 \%$ from hydro and $2.5 \%$ from coal. Hence for calculating the TIEC and EGHG of national grid the normalized value of are calculated. 
Table 4. Cost for Total Internal Energy Consumption (TIEC) and Emission of Greenhouse Gases (EGHG) [108]

\begin{tabular}{ccc}
\hline & TIEC $\mathbf{( M J / k w h )}$ & EGHG Kg/kwh \\
\hline National grid & 10.08 & 0.59 \\
Natural Gas & 10.08 & 0.51 \\
Diesel & 10.63 & 0.818 \\
Solar & 3.6 & 0.029 \\
Wind power & 0.103 & 0.009 \\
Biogas & 10.51 & 0.027 \\
Biogas with Fertilizer & 10.51 & 0.027 \\
\hline
\end{tabular}

From different energy mix mentioned in figure 4 the TIEC and EGHG is calculated using table 4. The optimality of TIEC and EGHG is shown in the figure 7,

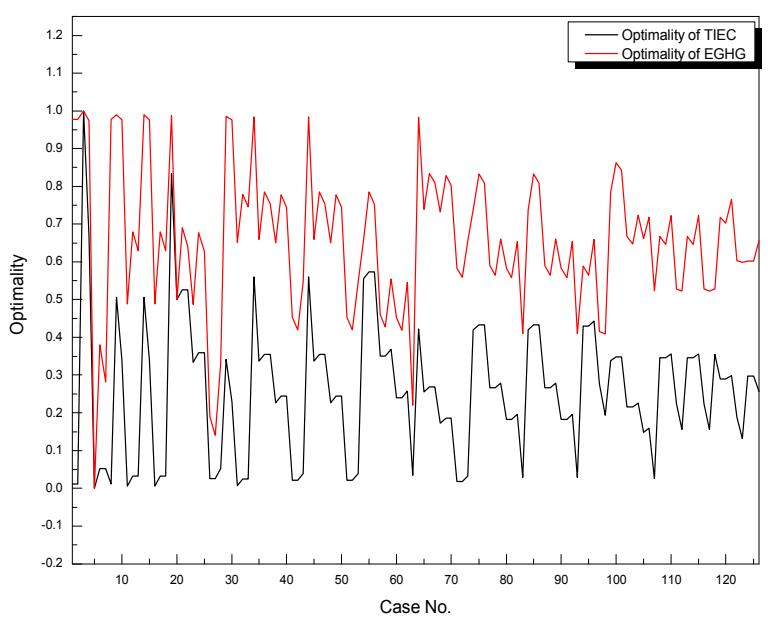

Fig 7. Optimality of TIEC and EGHG of different cases based on the energy mix mentioned in figure 4.

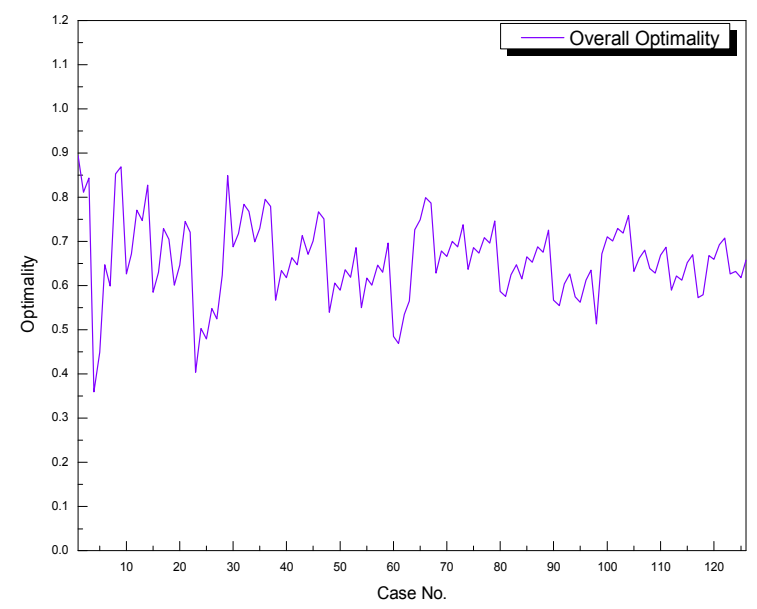

Fig 8. Overall Optimality of different cases based on the energy mix mentioned in figure 4.

From optimality of costs TIEC and EGHG the overall optimality of different energy mix is calculated using equation 12 . Figure 8 shows the final optimality along with the optimality of costs, TIEC and EGHG. From figure 8 it is seen that $100 \%$ biogas with fertilizer production has the highest overall optimality. But is not sure whether biogas from poultry waste alone can supply the required power or not. A month wise study of projected generation from biogas alone is done and a comparison is made with the monthly consumed power of PPL.

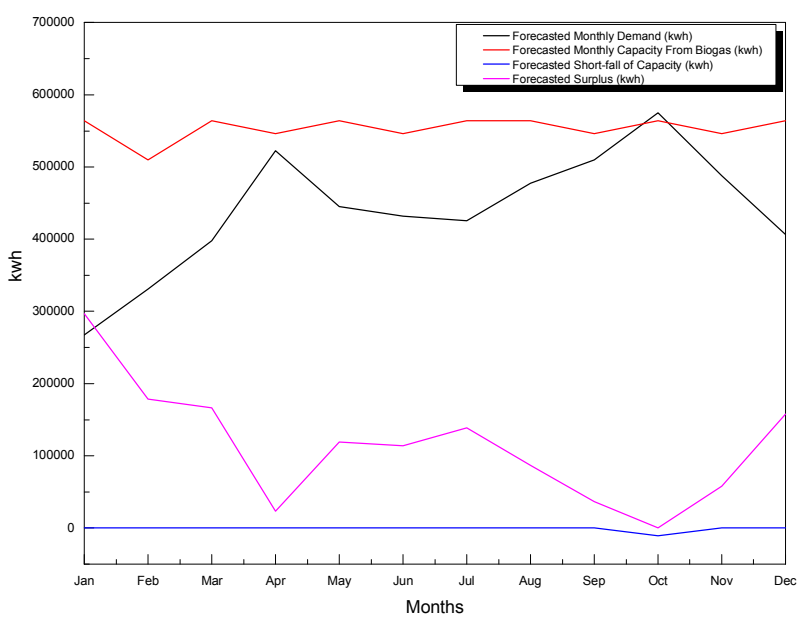

Fig 9. Forecasted Scenario using biogas as the primary source of energy.

Apart from month of October forecasted capacity from biogas is always greater than the forecasted demand. The capacity short falls by on $0.2 \%$. In other months a sizeable surplus is accounted. Hence additional gas holders can be used for supplying the additional required power in the month of October. Besides, the surplus electricity can be sold to the neighboring area or to the national grid for earning revenue. Finally it can be said that $100 \%$ power can be produced from the biogas alone which will make the poultry farm self sufficient in terms of energy.

\subsection{Optimal Unit Sizing for Power System with Biogas Plant Only}

For determining the optimum unit size and number different size and number of generators are assumed to be operational. There are 4 cases which are presumed to be operational at PPL. Out of these four cases best case is selected which will reduce costs, increase plant utilization factor and capacity factor and decrease overall biogas consumption. All the four cases are mentioned in the table 5 below,

Table 5. Different unit size for determining the optimum unit size

\begin{tabular}{ccccc}
\hline \multicolumn{5}{c}{ Biogas Unit Size and Number } \\
\hline Case No & $200 \mathrm{kw}$ & $300 \mathrm{kw}$ & $400 \mathrm{kw}$ & $500 \mathrm{kw}$ \\
1 & 8 & - & - & - \\
2 & - & 5 & - & - \\
3 & - & - & 4 & - \\
4 & - & - & - & 3 \\
\hline
\end{tabular}

The optimality of costs $\left(\mu_{\mathrm{TCG}}(\mathrm{k})\right)$ is calculated using capital and O\&M cost using equation 23. The below figure 10 shows the optimality of different cases. There are two types of optimality of costs e.g.-optimality of capital and optimality of O\&M costs. The optimality of costs is calculated taking the average of them. 


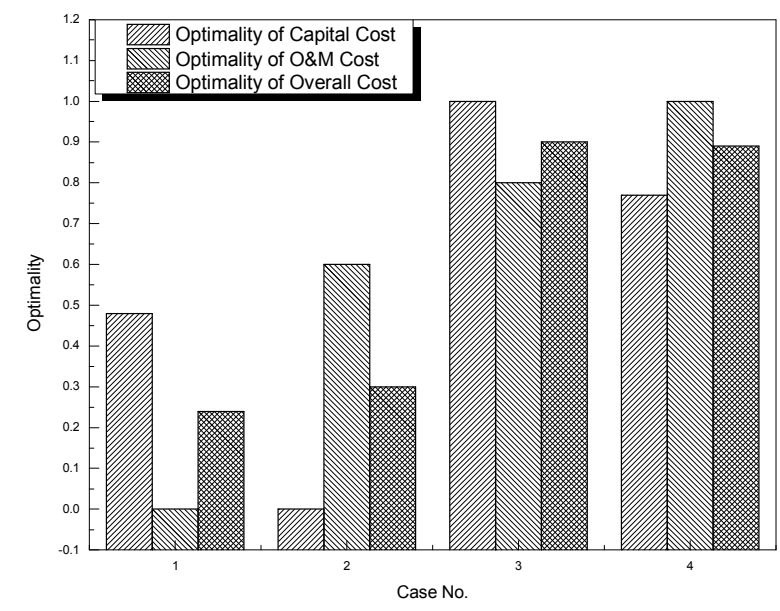

Fig 10. Optimality of costs for different combinations of generator unit sizes

Biogas plant with four $400 \mathrm{kw}$ generator has the highest optimality in terms of costs as per figure 10. Optimality of unused biogas, plant capacity factor and plant utilization factor are calculated using equation 24, 25 and 26 respectively. The optimality of biogas usage has two facets e.g. - additional biogas equivalent energy requirement and unused biogas. As seen earlier that, projected generated power theoretically fulfill energy requirements of PPL. But practically as it difficult to exactly match the load curve hence sometimes some energy is lost due to the below rated load operation of generators. Consequently some additional energy may be required from other sources. The optimality of additional biogas equivalent energy requirement and unused biogas are given by the figure 11 below. The average of these two is denoted as the optimality of energy usage.

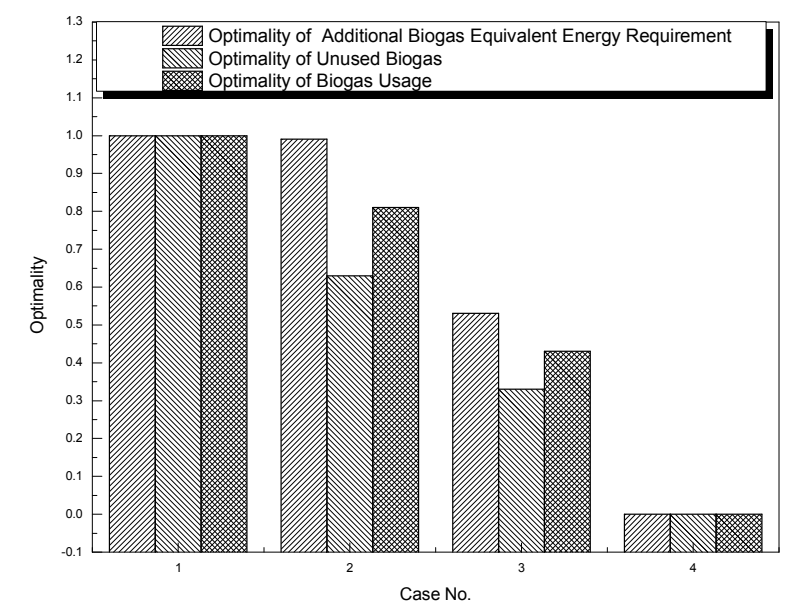

Fig 11. Optimality of biogas usage for different combinations of generator unit sizes

Optimality of plant capacity factor and plant utilization factor are given by the figure 12 below. The average of these two gives the optimality of plant utilization.

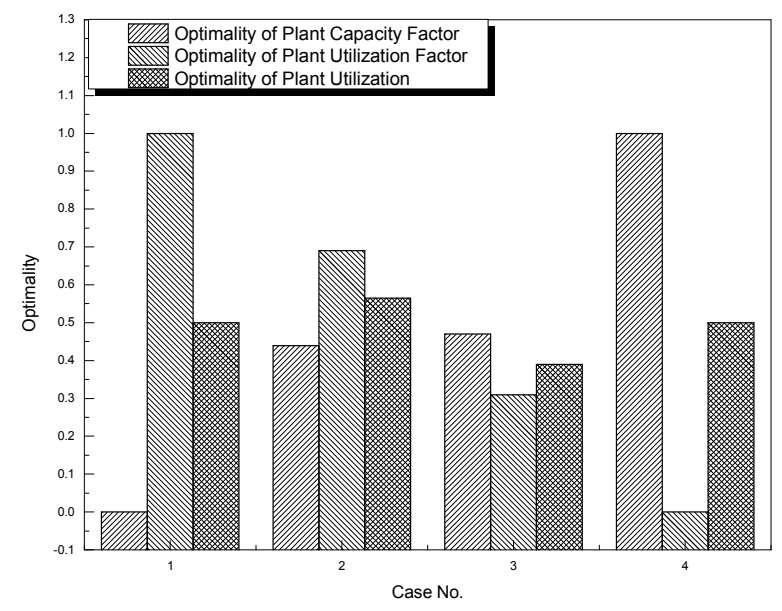

Fig 12. Optimality of plant utilization for different combinations of generator unit sizes

The optimality of combined biogas usage and plant utilization is calculated from the optimality of biogas usage and optimality of plant utilization. The optimality of combined biogas usage and plant utilization is shown in the figure 13 below.

It is seen that case 1 which is eight generators of size $200 \mathrm{kw}$ has the highest combined biogas usage and plant utilization optimality. This is very much understandable as smaller the unit better it fits to the load curve. But utilization should not be the only parameter to selecting the optimum unit size. Because for increasing the overall utilization the costs of increased. The average of optimality of costs and optimality of combined biogas usage and plant utilization gives the final overall optimality. Figure 14 shows the overall optimality of all four cases.

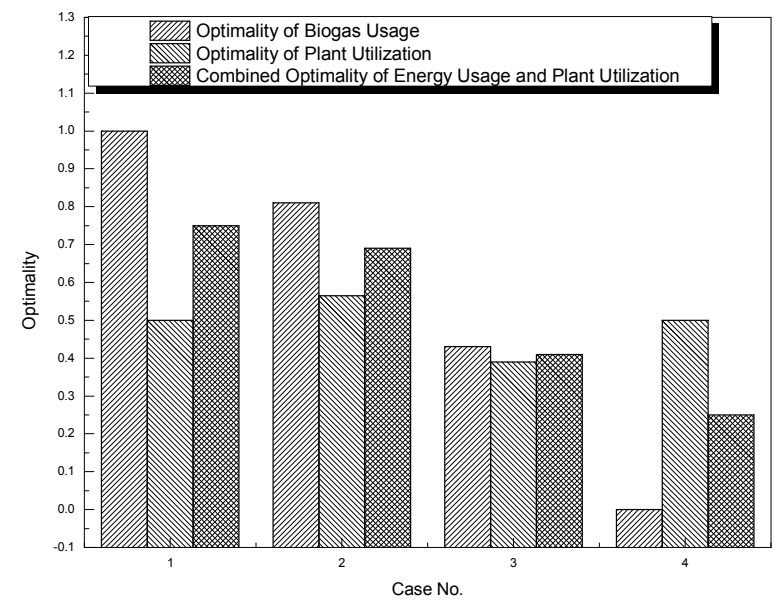

Fig 13. Optimality of combined biogas usage and plant utilization for different combinations of generator unit sizes 


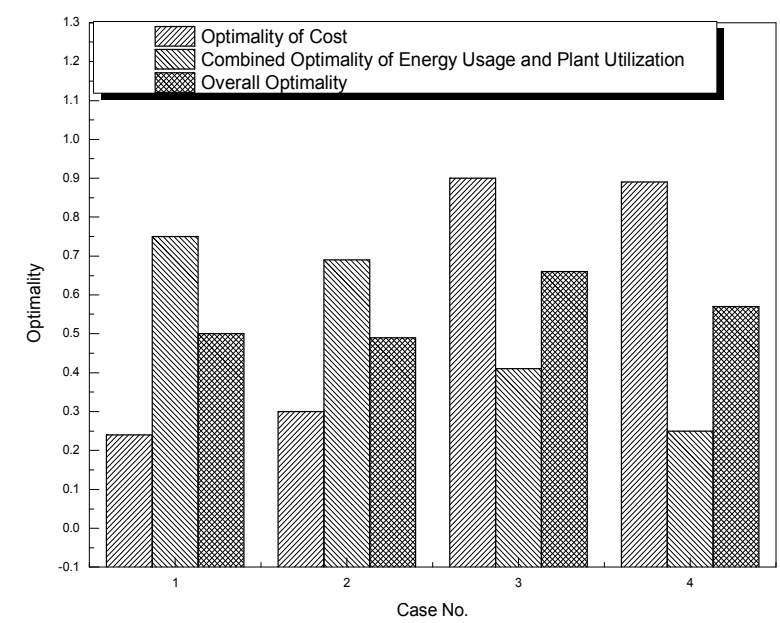

Fig 14. Overall optimality for different combinations of generator unit sizes

Though for PPL generators size of $8 \times 200 \mathrm{kw}$ gives the best utilization but $4 \times 400 \mathrm{kw}$ gives the best results in terms of costs as well as the gas usage and plant utilization.

\section{Discussion and Conclusions}

It is seen that there are number of energy sources which a poultry farm can choose from. A poultry farm can use any of these energy sources or a mix of them of different proportion. There are possible 7 energy sources singled out e.g.-National grid, natural gas, solar, diesel, biogas without fertilizer and biogas with fertilizer. All them have different pros and cons, and come at different prices. These sources emits different amount of greenhouse gases and have different energy efficiency. Hence not every source or possible mixes of them are economically and environmentally viable. So, for every poultry farm right mix of energy must be selected to minimize costs and greenhouse gas emissions. Paragon Poultry Limited (PPL) near Dhaka at Gazipur has been taken as reference for case study to select the right mix of energy of a poultry farm. At present PPL has three $500 \mathrm{kw}$ natural gas and one $200 \mathrm{kw}$ diesel generators. They don't draw power from national grid. They also have a biogas plant of $260 \mathrm{kw}$ where only a portion of daily poultry waste is used. With remainder of the waste they can set additional much bigger biogas plant which can make the poultry farm self sufficient in terms of energy. But it is not known whether biogas plant is cost effective or not compared to the mentioned energy sources. 126 different cases are identified where different mixes of energy from different sources are selected to find the best case where total costs will be minimized, greenhouse gases emission will be reduced and energy efficiency will be increased. It is found that a $100 \%$ biogas with fertilizer production has the highest optimality out of those 126 cases. In this the biogas plant can supply the required energy to the poultry farm itself, will generate revenue selling fertilizer and excess electricity. They can even generate revenue selling the excess biogas for cooking.

From the load curve of PPL is seen that there are two types of loads e.g.-base load and peak load. In addition there are two or more steeps of peak load. Consequently using only one generator unit is not efficient. For reducing the capital and O\&M costs, increasing plant utilization and energy efficiency generators should fit to the load curves perfectly. For doing so multiple generators are required. One generator should supply the base load and other generators to supply the peak load. For selecting the right unit size and number there are four possible cases been identified with the available biogas generator unit. It is found that four biogas generators of size $400 \mathrm{kw}$ have the best optimality.

Out of over two hundred thousand, only PPL has been taken four case studies for determining the right mix of energy and right unit size. It is found that $100 \%$ biogas generation with fertilizer production has the best optimality for energy mix and four 400kw generating unit has the best optimality. But this is not universal as constraints are different for different biogas plants.

\section{Acknowledgements}

The authors would like to acknowledge the contribution of Paragon Poultry Limited (PPL), Felix Energy Services, and Computerized Service Centre for their data of biogas plants. They are also grateful to CES (Centre for Energy Studies), IAT (Institute of Appropriate Technology) and CERM (Centre for Environment \& Resource Management) of BUET (Bangladesh University of Engineering \& Technology) for their support.

\section{References}

[1] A. Y. Saber and G. K. Venayagamoorthy, "Efficient Utilization of Renewable Energy Sources by Gridable Vehicles in Cyber-Physical Energy Systems” IEEE Systems Journal, Vol. 4, No. 3, pp. 285-294, 2010.

[2] M. H. Nehrir, C. Wang, K. Strunz, H. Aki, R. Ramakumar, J. Bing, Z. Miao and Z. Salameh, "A Review of Hybrid Renewable/Alternative Energy Systems for Electric Power Generation: Configurations, Control, and Applications" IEEE Transactions on Sustainable Energy, Vol. 2, No. 4, pp. 392-402, 2011.

[3] Paragon Pultry Ltd, " Green Power Plant: A new Generation of Green Farming" Bhabanipur, Gazipur, August 2010.

[4] S. A. U. Zaman "The Potential of Electricity Generation from Poultry Waste in Bangladesh. A Case Study of Gazipur District" M.Sc.-Thesis, University of Flensburg, Germany, August 2007.

[5] Z. M. Hasib, M. J. Hossain, S. Biswas and A. Islam, "BioDiesel from Mustard Oil: A Renewable Alternative Fuel for Small Diesel Engines" Modern Mechanical Engineering, Vol. 1, No. 2, pp. 77-83, 2011.

[6] M. B. Mollah, "Design and cost analysis of biogas based 
power plant for commercial usage: Bangladesh perspective," 2nd International Conference on the Developments in Renewable Energy Technology (ICDRET), pp. 1-6. January 2012.

[7] L. Ducksu, P. Jungsung, S. Haekyeong, C. Youngjun, L. Hakju and C. Jaeho, "Microgrid village design with renewable energy resources and its economic feasibility evaluation," Transmission \& Distribution Conference \& Exposition: Asia and Pacific, pp. 1-4. 2009.

[8] A.K. Hossain and O. Badr, "Prospects of Renewable Energy Utilization for Electricity Generation in Bangladesh," Renewable and Sustainable Energy Reviews, Vol. 11, Issue 8, pp. 1617-1649, 2007.

[9] S. C. Bhattacharyya and G. R. Timilsina, "Energy Demand Models for Policy Formulation: A Comparative Study of Energy Demand Models," The World Bank, Policy Research Working Paper - 4866, 2009.

[10] A.K.M.S Islam, M. Islam, and T. Rahman, "Effective Renewable Energy Activities in Bangladesh" Renewable Energy, Vol. 31, Issue 5, pp. 677-688, 2006.

[11] M.R. Islam and M. R. A. Beg, "Renewable Energy Sources and Technology Practice in Bangladesh" Renewable and Sustainable Energy Reviews, Vol. 12, Issue 2, pp 299-343, 2008 .

[12] S.I. Khan and A. Islam, "Performance Analysis of Solar Water Heater" Smart Grid and Renewable Energy, Vol. 2, No. 4, pp. 396-398, 2011.

[13] M. Uddin, and Q. Ahsan, "Expected status of natural gas in Bangladesh in meeting the electricity demand in the next twenty five years" Proceedings of the 3rdInternational Conference on Electrical and Computer Engineering ICECE, Dhaka, Bangladesh, pp 470-473, 28-30 December, 2007.

[14] A. K. M. A. Quader, and E. Gomes, "An Exploratory Review of Bangladesh Gas Sector: Latest Evidence and Areas of Further Research" Centre for Policy Dialogue, Bangladesh, Dhaka, 2002.

[15] Statistical Year book of Bangladesh 2009, Bangladesh Bureau of Statistics, Agargaon, Dhaka, Bangladesh, 2011.
[16] A. K. M. S, Islam and M. Islam, "Status of renewable energy technology in Bangladesh" ISESCO Science and Technology Vision, Vol-1, pp. 55-60, 2005.

[17] F. Nasiri and G. H. Huang, "Capacity Planning for Electricity Generation with Energy-Environmental Targets" Energy Sources - Part B: Economics, Planning \& Policy, Vol. 3, pp. 259-279, 2008.

[18] M. A. Gofran and M. Asrafuzzaman, "IDCOL Biogas Plant Construction Manual" Infrastructure Development Company Limited (IDCOL), 2007.

[19] Biogas Project Training Material of LGED, Local Government Engineering Department, Bangladesh 1999.

[20] K. U. Islam, " Practical data sheet about the running biogas plant of Bangladesh" Sustainable Energy for Development (SED), GTZ, Gulshan 2, Dhaka-1212, Bangladesh, 2010.

[21] Grameen Shakti "Integrated Rural Energy and Waste Management System through Biogas Technology" Green Solutions, Dhaka, Bangladesh, 2013.

[22] M. V. Haren, and R. Fleming, "Electricity and Heat Production Using Biogas from the Anaerobic Digestion of Livestock Manure - Literature Review" Ridgetown College - University of Guelph, Ridgetown, Ontario, Canada, NOP $2 \mathrm{C} 0,2005$.

[23] A. Mehta, "The Economics and Feasibility of Electricity Generation using Manure Digesters on Small and Mid-size Dairy Farms" Department of Agricultural and Applied Economics Energy Analysis and Policy Program. University of Wisconsin - Madison, 2002.

[24] A. H. Mondal and M. Denich, "Hybrid Systems for Decentralized Power Generation in Bangladesh" Energy for Sustainable Development, Vol. 14, pp. 48-55, 2010.

[25] P. C. Ghimire, "Technical Study of Biogas Plants Installed in Bangladesh" Infrastructure Development Company Ltd. (IDCOL), 2005.

[26] V. Jerković, Z. Špoljarić and D. Šljivac, "Stability Testing of a Small Biogas Plant in an Electric Power System" International Journal of Electrical and Computer Engineering Systems, Vol. 2, No. 2, pp.49-54, 2011 